\title{
Figurabilidad fílmica: el estatuto pictográfico del cine
}

\author{
Caché| Michael Haneke | 2005
}

\section{Derek Humphreys"}

\author{
Maître de Conférences en Psychopathologie Clinique et Psychanalyse \\ UTRPP - EA 3413 / Université Paris 13 - Sorbonne Paris Cité
}

Recibido: 10 de febrero 2018; aceptado: 10 de abril 2018

\section{Resumen}

Lo real, la experiencia, son del orden de lo discontinuo, de lo fragmentario. A partir de estos pedazos de percepción, la secuencia de imágenesen-movimiento permite la organización de un relato, de un guion que permite disfrazar el horror de la mirada, de lo real, detrás de una supuesta continuidad. ¿Imaginaria o fantasmática, qué valor dar a estas secuencias? Jugando con la velocidad y el movimiento, la producción de David Lynch restituye ciertas series fantasmáticas desarticuladas, remitiéndonos al sentido primero del fantasma como imagen icónica. Por su parte, Raúl Ruiz parece construir jeroglíficos a partir de las imágenes fantasmáticas de la escritura de Klossowsky, haciendo aparecer el elemento faltante dentro de un juego de iconos, vacíos y suspendidos, en "la hipótesis del cuadro robado". Engaño o necesidad, la construcción de una imagen-movimiento como fundamente de un relato permita la integración de la experiencia, incluso aquella del trauma, desarrollando así las instancias de reconocimiento social, de la novela individual, del mito colectivo, de una cultura y de una historia. Es a partir de esta reflexión sobre el valor de la imagen icónica en el cine, en su relación al fantasma y al relato civilizador, que este artículo analiza el personaje ausente en el film Caché de Haneke y su relación à la reconstrucción (o a la ausencia de construcción) histórica y traumática de la guerra de Argelia en Francia.

Palabras Clave: Figurabilidad | Imagen/Imaginario | Sueño | Fantasma | Inscripción colectiva del trauma

\section{The hypothesis of the hidden painting}

\begin{abstract}
Reality, experience, are of the order of the discontinuous, the fragmented. From these pieces of perception, the sequence of images-in-movement is used to organize a narrative, a script that disguises the horror of the gaze, the real behind the continuity. Imaginary or fantasy, which status should we give to these sequences? Playing with speed and with movement, the filmic production of David Lynch restores disarticulated fantasmatic series, referring to the original meaning of fantasm as an iconic image. On the other hand, Raul Ruiz seems to make rebuffs from the phantasmal images of Klossowsky, revealing the missing element in the set of empty and suspended icons we find in the "hypothesis of the stolen painting". Lure or necessity, the construction of an image-movement as the basis of a narrative allows to integrate the experience, including that of trauma, deploying also instances of social recognition, an individual novel, collective myths, of a culture and a history. It is from this idea on the status of the iconic image in cinema, and its link to the fantasy and the civilizing tale, that we will analyze the absent character in Haneke's Hidden (2005).
\end{abstract}

Key Words: Representability | Image/Imaginary | Dream | Phantasy | Collective inscription of the trauma

Una analizante me contaba, hace algún tiempo, el sueño que había hecho la noche anterior: "Es la guerra civil. Son imágenes violentas, como las que pasaban por las noticias anoche. Hay unos hombres armados [...] Tengo que ponerme un traje de baño, una especie de body transparente que me parece demasiado seductor, una especie de prenda de bailarina de strip-tease. Las otras mujeres no parecen incómodas, incluso una me dice que así, después de la fiesta, haremos un strip-tease [...] luego estoy con mi hija (de 4 años), había unos monstruos, unas especies de iguana-rana, yo trato de calmarla diciendo que son muy simpáticas”.

Inmediatamente, de manera espontánea, comienza a asociar: el resto diurno de los militares que vio cerca de su casa, "algo pasaba... esas situaciones me angustian horriblemente, las manifestaciones y todo eso... me aterroriza pensar que la policía me ataque". Dice que cuando tenía 13 o 14 años, en la época de las grandes manifestaciones de Greenpeace, ya representaba 18, y durante un paseo con sus tíos en un kleinbus Volkswagen la policía

derek.humphreys@gmail.com 
los detuvo por un control: "los dos rubios de ojos claros en el Volkswagen, era una cosa, pero conmigo entre medio todo se hacía sospechoso". Luego asocia a algunas escenas de las estaciones de tren de la periferia de París, donde vivían sus padres: "era una época en la que había esas especies de tropas de asalto en el metro... a menudo detenían a algún joven árabe solitario que se encontraba en el andén en ese momento... ¡la estación como escena para un espectáculo de esos jóvenes! ¡Registrado contra un muro por delito de mala cara! [...] al pobre no le quedaba más que hacer que inclinarse, bajar la mirada... más tarde fueron los viajes a Estados Unidos, la llegada al aeropuerto, con un pasaporte francés y un nombre de consonancia árabe... típicamente, era un please follow me... en el que era interrogada, me tenía que desvestir... es por eso que cuando decidí tener a mi hija, elegí vivir en el barrio más acomodado de París, donde en lugar de tener un apellido de inmigrado magrebí, podía ser una rica Libanesa instalada en Francia”. Dice, luego, que le parece que su abuela transportaba bombas en algún momento, y que sus tíos paternos fueron torturados, pero parece no conocer bien la historia de esta familia, que se quedó en el Magreb. Su madre no tiene los mismos orígenes, y a ella nunca le gustó la vida que se vivía allá en el norte de África. Es probablemente por eso que viajó sólo tres veces "la última, tenía solo seis años, estábamos en la playa y yo hacía la figura de una mujer en la arena, con todos los detalles, las redondeces del cuerpo... un tipo que caminaba por la playa se acercó a pisotearla y luego fue a gritar e insultar a mi padre... tuvimos que partir de la playa, y nunca volvimos a viajar... mi padre era francés... algunas amigas dicen "ah, eres de origen magrebí... pero ni se nota”.

Me parece notar una cierta disonancia en la palabra que elige para referirse al body seductor (aguicheur), y le pido asociar. Asocia a afilar, cuchillo, lo que nos abre el acceso a una nueva serie de asociaciones "en quinto cuarto grado, a los 9 años, nos gustaba ponernos vestidos en el verano, pero como los chicos jugaban a mirarnos los calzones, nos poníamos pantalones cortos debajo del vestido... un día un chico más grande me tiró contra un muro y puso su mano entre mis piernas".

Este relato pictográfico del sueño es paradigmático del modo en el que el psicoanálisis trata las imágenes del sueño: tres cuadros que constituyen un jeroglífico, un acertijo: una escena violenta, una segunda escena cargada de erotismo en torno al cuerpo femenino, luego una última, nuevamente entre mujeres, que habla de monstruos, de apaciguamiento y de diferencia de generaciones en- tre una madre y su hija. Estos tres cuadros intensamente cargados de afecto constituyen, juntos, un relato enigmático. Freud afirma al respecto que "el contenido onírico es [...] dado en una escritura icónica (en imágenes) cuyos signos deben transponerse (ser transferidos) uno a uno en el lenguaje de los pensamientos del sueño. Sería [...] engañoso si, en lugar de leer estos signos de acuerdo a su relación simbólica (según su relación entre signos), se leyeran de acuerdo con su valor icónico (su valor de imagen) [...] las palabras que se ensamblan así ya no tienen solo sentido, sino que pueden ofrecer la más bella y las más sensatas letras poéticas". ${ }^{1}$

El tejido lingüístico de este relato no es, por lo tanto, el de la narratividad del guion de un blockbuster, en el que las imágenes tienden a ir cada vez más rápido, favoreciendo la tensión hipnótica de un espectador atrapado por la espera del momento de caída de tensión del desenlace. Habría que situar esta tela lingüística, este género discursivo, del lado de la imagen-discontinua-puesta-en-movimiento en la constitución de una secuencia fílmica. Esta diferencia fundamental hace que algunas películas constituyan una superficie a ver, y otras un objeto que se mira; la posibilidad de ocultar un "motivo" detrás del señuelo de la continuidad imaginaria o, por el contrario, la emergencia inquietante de la discontinuidad de lo visible, que aparece de manera sensible por efecto de la inadecuación de la serie. ${ }^{3}$ Forzando en cierto modo la mirada sobre el motivo (fantasmático) escondido. ${ }^{4}$

Este artículo se interesa así por la dimensión pictográfica de ciertas películas que, en su manera de permitir que una forma de figuración aparezca en la construcción de cada escena o en la introducción de un elemento de discontinuidad, otorgan a la imagen un valor cercano al de los efectos de las producciones del lenguaje en psicoanálisis. Estas películas "presentifican” y, a su manera, conducen a la elaboración de contenidos que han conservado un carácter enigmático. También consideraremos en este artículo, a partir de la idea de una posibilidad de presentificación colectiva, la capacidad de acompañar la inscripción y la construcción colectiva (de un pueblo, de una nación) de la narrativa del trauma.

\section{La hipótesis del cuadro...}

Klossowsky escribió en 1965 "Le Baphomet”. Una historia en la que un grupo de monjes sin tiempo ni lugar olvidan el cuerpo para convertirse en puro aliento. Cuerpos que se convierten en lenguaje, bocanadas de 
pura intensidad, de la pura violencia hiper-sexualizada que Deleuze califica de "pornografía superior": aquella de las imágenes del éxtasis de Teresa de Ávila. Interesado por la cuestión del simulacro, de la inspiración, del cuerpo y del enigma, Raúl Ruiz comienza a trabajar con Klossowsky en la realización de la película "La hipótesis de la pintura robada" (1979).

En la película de Ruiz, el espectador toma el papel de un visitante invisible, que intenta establecer los vínculos ocultos entre las pinturas de una serie con el fin de dilucidar la escena que falta, la de un cuadro de la serie que ha sido robado. El protagonista, que es el coleccionista de la serie, acompaña al espectador en esta elucidación utilizando la técnica de los "cuadros vivos": la reconstrucción

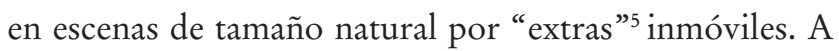
través de las indicaciones del narrador en off, de su pura voz, la película se organiza en torno a la búsqueda del ángulo preciso, el punto de vista correcto para la organización de la escena, la orientación única de la luz, la "Einstellung” que revelará el elemento faltante. El "motivo secreto" permanecerá oculto hasta el final de la película. Al final del enigma, la reconstrucción culmina en una ceremonia oculta e incorpórea alrededor del Baphomet.

La organización óptica que determina el punto de fuga y las leyes de la perspectiva, lo que se saca a la luz, no trata de fijar aquí una narración a partir de una continuidad de imágenes en movimiento, sino que se limita a presentar-darstellen- una serie de puestas en escena. La actualización de estas representaciones levanta el velo enigmático de la suspensión propia a la discontinuidad. El espacio entre cada escena adquiere así un carácter fantasmático. Esta investigación clínica, que conduce a un acertijo que es necesario descifrar, delimita un espacio enigmático que excede el nivel de cada imagen y también el de la serie.

\section{Lo que permanece oculto}

He desarrollado durante estos últimos años el problema de la inscripción del trauma en la cultura y el papel de esta inscripción en la memoria en la elaboración del trauma, tanto en el caso de un evento singular (violación, y el problema de las llamadas "células de intervención de crisis") como en la historia de los pueblos (violación como violencia de estado, tortura, desaparición organizada). Como parte de esta investigación, pude ver que la generación que está entre los 20 y 30 años de edad en Francia no se sentía concernida por estas preguntas.
La película de Haneke, Caché (Escondido), ${ }^{6}$ parece haber dejado a muchos jóvenes franceses completamente indiferentes. Ciertamente no es su mejor película: la violencia y el cinismo que vincula sus conciudadanos a la historia del Nazismo aparece de manera mucho más sutil y explicita en sus primeras películas, Benny's videos, El séptimo continente o 71 fragmentos de una cronología de la casualidad. De manera más amplia, ha puesto en escena la violencia fantasmática y la relación entre el sujeto fílmico y televisivo y el sujeto onírico en Funny games, La pianista o Das weiße Band. Pero el movimiento permanente entre la secuencia de la película y las grabaciones por parte de un observador, que avanza y algunas veces se superpone con voces en off o desfasadas respecto de la imagen, tomando de modos y ángulos diferentes las mismas composiciones escénicas (de nuevo la Einstellung), crea una sensación ominosa de cuestionamiento de la relación de la verdadero a lo falso. El punto de vista de la cámara evoca, por lo demás, el de las cámaras de videovigilancia que introduce también, en un guiño al autómata, la dimensión de lo Unheimliche. Me parece así que Haneke articula en esta película de manera excepcional, a través del ocultamiento y de la falsificación, la compleja relación de los franceses con su historia reciente sin perder por ello la distancia que requiere su no-pertenencia y su ignorancia subjetiva de ciertos episodios oscuros.

Caché (Escondido) es una película sobre lo que se muestra, lo que se da a ver sin perder su carácter enigmático. La trama se organiza en torno a un enigma inquietante, de violencia y desaparición, que se desencadena cuando la vida cotidiana de una familia es filmada y registrada sin poder comprender cómo, cuándo ni por quién. En estas grabaciones, la mirada desfasada, casi forzada, de lo habitual y cercano, producen un efecto monstruoso, en el que lo familiar aparece como inquietante, Unheimliche: lo que se muestra es justamente aquello que no puede ser integrado en la continuidad imaginaria de lo visual. La película pone en escena, a través de esta inquietud familiar, una culpabilidad invisible, indecidible, en torno a los acontecimientos de octubre de 1961: la represión violenta, por parte de la policía francesa, de hombres, mujeres y niños argelinos convocados por el FNL para manifestar en las calles de París contra el toque de queda aplicado en el norte de África, en la época en que Maurice Papon era Prefecto de Policía. El número exacto de muertos que produjo esta intervención policial no ha sido determinado hasta el día de hoy, y los eventos que tuvieron lugar en los 
centros de internamiento parecen no formar parte de la memoria colectiva.?

Nada sucede en las grabaciones de la vida ordinaria de una familia parisina: estacionar el auto al final del día, sacar la basura, partir al día siguiente al trabajo... la secuencia provoca, sin embargo, una tensión entre el ritmo de la serie fílmica y el de los videos en los que la familia se descubre grabada. La sensación de inminencia de algo grave o violento se instala progresivamente, la amenaza se substituye a la inacción. Este suspenso empuja al protagonista a buscar el significado de este sentimiento perturbador. Así, la mirada exterior, amenazante, se convierte en un sentimiento de culpabilidad proveniente de una mirada interna. Esta culpa aparece toma la forma de un enigma, que se asemeja a la sensación del niño siente haber hecho algo inapropiado... a menos que hayan sido sus padres quienes podrían haber hecho algo impensable y que aparece como borrado de la historia familiar. Resulta especialmente interesante la escena de diálogo vacío o ausente en el momento en el que el protagonista decide ir a visitar a su madre anciana con la esperanza de saber más sobre la historia familiar, pero ni la madre ni el hijo parecen tener algo que decir, salvo eludirse mutuamente, eludir los hechos. Este intercambio vacío es cerrado por una escena de reencuentro faltante, cortada del montaje.

En su evolución, la película nos deja entrever que los trabajadores agrícolas que se ocupaban de las tierras de los padres del protagonista, provenientes de Argelia, habrían desaparecido durante las manifestaciones de octubre del '61, dejando solo a un niño, Majid, en la casa de campo. Casi como una reparación ante esta desaparición que no parece haber sido comentada ni nombrada, los padres habrían considerado la adopción de Majid, pero rápidamente cambian de opinión y deciden entregarlo a los orfelinatos del estado. Esta historia, que se reconstituye a partir de una serie de elementos desmigajados, es conservada hasta el final de la película como un secreto o es apenas enunciada, fragmentariamente, por el protagonista. Haneke deja entrever, sin embargo, que todas las reacciones y miedos del protagonista están determinados por este incomprensible y enigmático sentimiento de culpabilidad venido de un lugar desconocido... de algo que sus padres habrían hecho, o tal vez él mismo, en su crueldad infantil, o incluso la sociedad entera... Ninguna explicación es dada al espectador sobre las grabaciones ni sobre los dibujos recibidos por la familia y que desencadenan la trama. Toda la película se organiza sobre este vago sentimiento de culpabilidad. La escena final, y especialmente los créditos de cierre, refuerzan este aspecto enigmático vinculado a una transmisión transgeneracional, con el encuentro y una discusión (a cuyo contenido el espectador no puede acceder) entre el hijo de Majid y el hijo del protagonista, a la salida del liceo de este último. Los dos hijos se encuentran sin que sea posible determinar si ya se conocían o si se encuentran por la primera vez y si son (uno u otro) de alguna manera responsables de los videos (Haneke deja voluntariamente la duda al respecto porque, aunque habiendo escrito un diálogo, lo hizo inaudible y prefiere no comentarlo).

No pretendo criticar con este articulo la buena o mala construcción de la historia en Francia, y mucho menos hacer un comentario sobre su pasado colonial. Por otro lado, como psicoanalista, he podido reconocer este mismo nudo enigmático de culpabilidad indistintamente en analizantes chilenos, rumanos, españoles, alemanes, marroquíes o franceses. En mi experiencia con analizantes franceses, la imagen inmediata de esta culpa enigmática se refería a menudo a un padre, abuelo o tío que había participado en la guerra de Argelia, una historia familiar relacionada con Argelia o un tratamiento específico relacionado al retorno de Argelia después de la guerra. Argelia... La fisura se manifiesta, se hace siempre presente, pero sigue se muestra como una hendedura bien delimitada, escondida detrás de una pantalla. Haneke se permite interrogar esta pantalla con su película.

Habiendo yo mismo conocido una dictadura caracterizada por su capacidad encubridora, de ocultamiento ordinario, de una violencia cotidiana silenciada por las desapariciones que muchos adultos alrededor de mí podían justificar hasta el punto de "normalizar" la muerte y la violencia, esta película enigmática construida alrededor de un vacío me ha parecido inquietante, ha revivido un sentimiento conocido. A pesar de ello, muchas personas en Francia podrían considerarla como incomprensible, un puro vacío, y dar vuelta la página sin siquiera plantearse la pregunta que Haneke propone aquí. Cabe al respecto recordar la complejidad de la relación a la memoria y al trauma, como lo demuestra el efecto que tuvo la película de Claude Berri de 1997, en la que la resistencia y la colaboración se entrecruzan en torno a la historia de los Aubrac, al punto de haber tenido que recurrir a la organización de una gran mesa redonda de historiadores en la que se discutió la diferencia entre la escritura de la historia, la historicidad y la memoria. De la misma manera, la película de Haneke pone en evidencia la difícil elaboración de esta memoria respecto de la guerra de Argelia. 


\section{La función de la imagen en Freud}

En el tratamiento particular que el psicoanálisis puede hacer del cine, privilegiando el juicio sobre la imagen de la mirada por sobre la continuidad imaginaria de lo visual, resulta fundamental detenerse sobre las nociones de Bild y Traumbildung en la pluma de Freud. Es necesario recordar el contexto particular al que se refiere el tratamiento de la imagen en la formación del sueño, la Traumbildung: este Bild no es nunca una imagen simple, aquella que podemos asociar a la continuidad, la imagen con la que se construye el Yo. Se trata más bien de una imagen aislada, que habla por sí misma, sin reenviar a una continuidad; una imagen que se presta a un trabajo de deconstrucción, de traducción, una imagen sin valor simbólico. Para Freud, el sueño es un enigma en imágenes, un acertijo (Bilderätzel) que "nuestros predecesores ... han incurrido en la falta de considerar [...] como una composición pictórica. De este modo no tenía más remedio que parecerles insensato y sin valor alguno". ${ }^{8}$ Así es como Freud logra vincular una elaboración del pensamiento a una elaboración de imagen, más allá de toda secundarización y de todo respeto de los principios de no-contradicción.

La revolución epistémica freudiana es el resultado del valor particular que Freud otorga a la lengua, sacándola del registro del puro significado de las palabras para introducir, en 1895, la idea de la creación de una "comunicación mutua" en la apropiación del lenguaje por parte del bebé en sus primeros intercambios con el adulto que lo acompaña, con un Nebenmensch. ${ }^{9}$ La lengua se inscribe así en un sentido común, el del significado, en la medida en que el adulto que acompaña al bebé está inscrito, él también, en una cultura (es un Mensch). Es por este mismo efecto de asociación de la experiencia singular al encuentro con el otro y la cultura que la significación no es el único aspecto capaz de determinar el valor de los intercambios lenguajeros. En esta forma de pensar el peso afectivo que portan las palabras, a menudo independiente, a veces disociado de su valor de significación, Freud se aparta de la ortodoxia neurofisiológica de su tiempo para interesarse por los efectos creadores de la palabra poética, por el valor "desviado" de todos aquellos ruidos devenidos sonidos y luego palabras, tal como podemos encontrarlo en los sueños o en el "Witz", la broma, aquella palabra que cae en un momento justo y que, tan pronto la captamos en su desfase, en apertura hacia otros sentidos, introduce una brecha en la continuidad del discurso y de la escena que nos hace reír.
La situación que trato de elaborar aquí, en términos de acertijo traumático o pictograma del trauma, está vinculado a los mismos niveles de traducción/transcripción a los que se refiere Freud en su voluntad de comprender la relación aparentemente anacrónica entre la inscripción y la imagen en la producción del síntoma. Es, efectivamente, a través de la investigación clínica en torno al síntoma que Freud rápidamente comprende que, en la fantasía histérica, no debemos atribuir ninguna especie de simbolismo al evento psíquico (como lo habían hecho durante mucho tiempo los neurólogos, probablemente fascinados por la visualidad de la puesta en escena erótica del cuerpo histérico). Freud se aleja así del problema de la causalidad, formulando la hipótesis de una escena histérica que sería, en sí-misma, la causa de conflicto y una producción en espera de traducción, dirigida a un interlocutor capaz de interpretarla. ${ }^{10}$ Utilizando el modelo del jeroglífico, Freud asume la existencia de un código lingüístico completamente diferente y nuevo, que se produce específicamente en el contexto de la actualización transferencial. Es el momento en el que Freud decide, ante esta forma de visualidad de la pantomima histérica, dejar de ser el adulto que entiende todo, como pudo hacerlo por ejemplo al insistir en la explicación a Dora sobre su repugnancia por lo sexual. Desde entonces, la posición de Freud no será más la del adulto que sabe sino la del investigador que trata de descifrar la escena en su contexto. Freud asume así el rol de figura paternal que trata de comprender. Es en este enfoque, y más allá de cualquier aspecto técnico, que Freud escucha la Darstellung como "puesta en acto" (y no como guion) del fantasma sexual infantil.

En un jeroglífico, no es porque haya tres aves que se puede decir que el sentido está en el número tres o en la llegada de las aves. Es necesario, en la lectura del jeroglífico, pensar en la posibilidad de registros diferentes de significación que dependen de detalles en los que puede incluso haber una presencia simultanea de varios registros de lectura. Así, podría importarnos retener si estas aves, por ejemplo, miran hacia el este o han sido representadas justo debajo de una imagen del sol, o incluso porque aparecen a la derecha de otro personaje. Es la atención que otorgamos a cada segmento de la "imagen" que hace que la figura pueda dar acceso al significado singular, a lo que algunos llaman un significante. Lo que me parece fundamental aquí es que este Bild no es una imagen en el sentido habitual de lo que representa otra cosa, de reflejo... cuando Freud habla de Bild en la Traumdentung, se refiere al pictograma, al acertijo, al conjunto de trazos que hace 
representación de manera enigmática. Por ello, sería un error reducir el significante a una pura cuestión fonética, un juego de palabras que solamente encuentra su aspecto creador en los malentendidos y las inadecuaciones entre lo dicho y lo escrito en francés y que ha generado tantas dificultades para comprender el trabajo de Lacan sobre el lenguaje y la escansión. Los códigos de la pantomima cambian constantemente, y el trabajo consiste ante todo en olvidar una dimensión inscrita en un simbolismo general para avanzar en la búsqueda de los encuentros capaces de conducir a la asociación de estas series aparentemente heterogéneas que determinan el "significante".

Es en la carta a Fliess del 6 de diciembre de $1896^{11}$ que, hablando de Übertragung (transcripción, transferencia) Freud logra diferenciar los múltiples registros, inevitablemente complejos, de la imaginación y de la representación, que lo conducirán, algunos años más tarde, a la formulación de un principio general de funcionamiento del aparato psíquico. Nuestra capacidad de traducir o de transcribir el pensamiento de Freud, tanto en francés como en español o en inglés, es bastante limitado: la posibilidad infinita de jugar et inventar palabras en alemán permite a Freud dar cuenta de los diferentes niveles de inscripción y de la traducción sucesiva de la imagen, deteniéndose en el rol y la importancia de cada uno de estos pasajes, de una manera que resulta impensable en otro idioma. Cada uno de estos pasajes juega, efectivamente, un rol fundamental, una relación específica cuando se trata de la figuración, de la organización del fantasma, de la formación de la imagen del sueño (en su relación con la cosa y el principio primario), respecto de la representación. Es por esta razón que nos vemos obligados a conservar el idioma de Freud, por ejemplo, para referirnos a la representación (que se trate de representación-palabra o de representación-cosa), ya que se refiere a registros diferentes cuando somos capaces de distinguir Darstellung, Vorstellung (sache-, wort-, Ding), Einstellung, o incluso Vorstellungsrepresentanz (¡que Lacan traduce como representante representativo de la representación! $)^{12}$ y que se reducen todos en español o en francés a la pura representación. Es en este sentido que me ha parecido interesante jugar con el sentido cinematográfico del término Einstellung... también podríamos añadir a esta complejidad la especificidad, por ejemplo, de un Austellung, otra sutilidad de la representación en sus niveles de relación a la imagen, a la inscripción y a lo real. Cada una de estas palabras caracteriza un estado, una forma diferente del Stellung, de lo que se ha presentado, de lo que tiene o toma posición.
Más allá de esta multiplicidad de planes que deben reconocerse en el trabajo sobre lo visual y la mirada en la organización del síntoma y de la narrativa, me parece necesario aclarar el valor que Freud otorga a la imagen en juego en la transferencia y en la actualización en la cura. Debemos para ello considerar primeramente la función del síntoma histérico, considerado por Freud como pantomima, y accesible solo a través de "fantasías" superpuestas (fantasías que adquieren un poco más tarde, en 1915, un carácter específico, en lo que ha sido llamado en su traducción francesa un "fantasma”). Un poco más tarde, en la carta del 21 de septiembre de 1997, cuando Freud afirma, explicando el papel constante de los padres en la "fantasía" sexual, que no hay evidencia alguna de la realidad en el inconsciente, resulta evidente que la transformación de la escena traumática debe pasar por fantasías que resultan de una retención de aspectos visuales que serán responsables de la organización del síntoma. De la pantomima al fantasma, esta asociación de series heterogéneas ${ }^{13}$ es el efecto de un "proceso de fusión y deformación análogo a la descomposición de un cuerpo químico combinado con otro [...] un fragmento de la escena vista está así conectado a un fragmento de la escena escuchada para formar una fantasía, mientras que el fragmento no utilizado entra en otra combinación [...] que termina en [...] el cese del síntoma". ${ }^{14}$ La fantasía sería producida a posteriori, como efecto de la comprensión ulterior del carácter de los elementos visuales o acústicos inscritos en la escena, y tendría un rol protector, cerrando el acceso al recuerdo y comportándose respecto de lo oído tal como lo hace el sueño respecto de lo que es visto ¿Es necesario aquí recordar que, para Freud, el fantasma reside en la construcción gramatical del relato y no en el síntoma al que se sustituye? Efectivamente, cuando nos concentramos en la búsqueda del aspecto psíquico de la imagen evocada, perdemos de vista la dimensión de lenguaje sobre la que reposa el fantasma -dimensión de gramaticalidad pletórica de sentido, en una dimensión que va mucho más allá del de la pura narratividad. Es por esto que nuestra atención es retenida por los detalles que "figuran" la escena, por los elementos periféricos del cuadro capaces de determinar contextualmente su significación. Solamente de esta manera podemos continuar nuestra investigación sobre la lengua singular de cada sueño; una lengua que no hace lenguaje, sino que conserva su calidad de enunciado inédito y, en este sentido, poco fiable en términos simbólicos... un enunciado cuyo valor debe reconocerse en términos de enigma o de poema. Oponiendo la solidez de la lógica aristotélica al 
sujeto de la enunciación, Lacan afirma que "es más acá de este intento de captura de la enunciación por las redes del enunciado que nosotros, analistas, nos situamos [...] en el sentido que es por allí que se produce la fisura [...] Coulourless green ideas sleep furiously hace sentido también. Es así que el psicoanálisis hace sentido por todos lados". ${ }^{15}$

Es a partir de esta reflexión que Freud llega a la formulación del sueño como una imagen que no se comprende y que no debe ser rápidamente interpretada, a través de la atribución de un sentido común. El sueño siempre pasa por un trabajo de construcción, de deformación, y es necesario encontrar el lenguaje al que pertenecen las imágenes que en él aparecen, de una manera siempre nueva, siempre diferente. La imagen del sueño es una imagen que el soñador mismo ve sin comprender. El sueño es así el paradigma de la descomposición por fragmentación con una ulterior recombinación, pero la memoria sigue siendo la única fuente del impulso sintomático.

Resulta interesante ver las películas de Lynch bajo este prisma, como una secuencia de fantasmas, cada uno bien organizado en los detalles visuales de color, temperatura y sonido sobre los cuales se organiza el fantasma; la serie de fantasmas que se superpone en el montaje exige el desciframiento del lenguaje que los conecta, dándoles un sentido, una interpretación. Esta necesidad de acceder al lenguaje implícito en la lógica del montaje resulta especialmente evidente en Mullholland drive o en Lost highway.

Freud es, al respecto, bastante preciso cuando nos invita a no dar un valor simbólico a las imágenes del sueño sino a considerarlas como bloques de imágenes: una imagen que va más allá del nivel metafórico cuya organización sigue diversos niveles de intensidad, como una antropomorfización. ${ }^{16}$ Como si de la imagen se desprendiera una especie de facies [visagéité] hecha de lenguaje. La carga afectiva que se teje alrededor de esta facies va más allá de la metáfora y se organiza de manera compleja, constituyendo una nueva figura.

\section{Películas, extras y figurabilidad}

Hablamos mucho sobre las claves que encierran los detalles que componen la imagen. Cuando se habla de la organización del fantasma, el detalle es la única forma de permanecer cerca de la formulación gramatical (la suspensión y la elisión del sujeto en tres tiempos propuesto en "Un niño está siendo golpeado") sin perderse en una interpretación sintética globalizante, que nos remitiría al universal simbólico. El lenguaje del sueño y el desciframiento del enigma del sueño dependen de elementos suspendidos en cada escena, transferidos (übertragen) uno a uno. En este sentido, el síntoma no puede ser aislado, sino que debe ser también concebido como un jeroglífico, en su contexto escénico contingente de actualización.

Es la materia que constituye los elementos periféricos lo que nos permite acceder a la clave de desciframiento de la escena: Kubrik se pasó meses viajando y visitando casas, ciudades y países en busca de $L A$ puerta frente a la cual el protagonista de "eyes wide shut" se detuvo -en un instante de mirada- durante dos segundos. Eisenstein construyó toda una transmisión cultural e histórica a partir de escenas colosales en las que los "extras" llevan todo el peso de la transmisión; Rossellini hace el neorrealismo italiano cuando enmarca la historia de los protagonistas de "Stromboli" en una red de movimientos y gestos tradicionales de pecadores, toda una tradición, un lenguaje que va mucho más allá del relato. Todos estos "extras", todos estos elementos de figuración constituyen la esencia de la historia de manera más intensa y radical que lo que puede hacer la trama narrativa lógica. Del mismo modo, dejamos de interesarnos por la serie lógica de la narrativa, bien organizada a través de la serie de imágenes, para centrarnos en torno del elemento enigmático de sueño y del fantasma a partir de fragmentos que trazan, de manera sutil, una figura que nos permite situar los códigos del lenguaje involucrado en la actualización (transferencial). Estos elementos de figuración nos permiten seguir el camino, la época, la materia de la que está hecho el fantasma en un proceso cercano al del sueño.

En Caché (Escondido), debemos ubicar los elementos de la figuración en la vida cotidiana, en el desdoblamiento de los personajes, en la repetición a diferentes velocidades de los mismos trayectos, de los mismos lugares. La suspensión de la imagen. El travelling del corredor de un edificio revela claramente esta dimensión ominosa, de Unheimliche. Pero resulta también necesario reconocer el elemento de falsedad, una especie de apariencia falsamente inquietante del niño que asusta al protagonista en sus pesadillas y que en su ridículo terror termina sacándonos de la continuidad fílmica, cuestionando su valor de veracidad. Haneke juega aquí con el doble, con lo falso, en los detalles, haciendo nuevamente entrar en escena lo ominoso, Das Unheimliche.

En las películas aquí evocadas, que se trate de Ruiz, Lynch, Kubrik o Haneke, es siempre en torno a la in- 
quietante suspensión de la continuidad que surge la figuración. La palabra elegida por Freud, ya sea que hable de histeria, de fantasma o de sueño, es siempre Darstellung. Este Darstellung es la manera en la que una película puede dar una primera forma a una experiencia traumática o enigmática, prestándole elementos contingentes, como si fuesen restos diurnos, en la construcción de una narrativa capaz de circular y hacer comunidad y cultura.

La función de Caché habría sido la posibilidad de interpelar construcción necesaria de una memoria colectiva, estableciendo una base de asentamiento para las figuras de elaboración de lo traumático / enigmático -de aquello que, no habiendo hecho inscripción sino pura efracción del psiquismo, no puede ser elaborado sin ser antes "realizado". Parece que esta película no tuvo éxito. ¿Se trata de una inscripción que todavía requiere tiempo? ¿Han podido estos elementos de figuración abrir un camino que estaría todavía en proceso de construcción? $\mathrm{O}$ bien, ¿podemos pensar que los medios cambian con las generaciones y la cultura, y que la cinematografía ya no constituye un medio, sino que esta inscripción se efectúa en nuestro tiempo a través de ese otro tiempo, esa otra materia que es la televisión, como tiende a creer Jane Campion cuando decide hacer "Top of the lake"? No olvidemos en todo caso el gran desprecio que ha manifestado Haneke por la imagen televisiva.

\section{Conclusión}

El sueño presentado al comienzo de esta reflexión nos ha permitido poner a trabajar la pregunta formulada por Haneke en Caché (Escondido). El trabajo de interpretación de las escenas vistas en una sala de proyección cinematográfica, en esta otra "sesión”, pertenece de cier- ta manera a lo colectivo.

El lenguaje porta en sí un quantum de afecto, y no es la simple imagen lo que interesa al psicoanálisis. Si tenemos que tratar la imagen cinematográfica en su impacto sobre la elaboración del trauma o de lo enigmático, ya sea a nivel individual o colectivo, hay que hacerlo desde la noción de Bild, como imagen suspendida en busca de un sentido que no puede ser atribuido por un significado común. El valor específico de estas construcciones en una sociedad depende de la capacidad de apropiación, por un pueblo, por una nación, de estas imágenes fantasmáticas y suspendidas, para compartirlas, haciendo posibles sus efectos colectivos e individuales, incluso muchos años después. El análisis de S. Arensburg de la situación de mujeres violadas durante la detención en una estrategia de Estado, y la imposible elaboración precoz por parte de estas mujeres de la dimensión traumática de estas violaciones sistemáticas sin la construcción previa de una memoria y de un reconocimiento colectivo del trauma y de la estrategia de estado, me parece ilustrar este aspecto. Sólo 15 años después de una primera iniciativa destinada a la elaboración del trauma asociado a esta estrategia de terror del estado chileno que estas mujeres fueron capaces de empezar a cuestionar los eventos en busca de respuestas y de elaborarlos como una experiencia que ha verdaderamente ocurrido, y luego como una estrategia destinada específicamente a ellas, como una manera de destruirlas. Es solo así que el trauma del cual fueron las víctimas puede ser inscrito y luego elaborado.

También es en este contexto que tomé la película $\mathrm{Ca}$ ché (Escondido), tanto para pensar cómo se organiza la historia en torno a un vacío enigmático, como respecto de los efectos que la presentación / figuración (Darstellung) pueden tener en el tiempo.

\footnotetext{
1 S. Freud (1900). La interpretación de los sueños. Aparece citada respectivamente la traducción de L. Lopez-Ballesteros y Torres (O.C., Tomo I, Madrid, 1948, p. 393-397), y la de J.L. Echeverry (Amorrortu IV, p. 285-286). étation du rêve (traduction de J.P. Lefebvre). Paris, Seuil 2010, pp. 319-320. Resulta interesante notar las variaciones entre las versiones, a veces significativas. Es el caso también entre la traducción dirigida por J. Laplanche (que ha elegido la expresión “escritura en imágenes” para referirse a Bilderschrift, que es traducido por J.P. Lefebvre como escritura ICONICA. Del mismo modo, Laplanche se refiere al valor de la imagen, en oposición a la idea de valor ICONICO defendido por Lefebvre en la traducción de la palabra Bilderwert. Finalmente, Zeichenbeziehung es traducido por Laplanche como relación entre ellos en tanto signes, lo que es interpretado por Lefebvre como une referencia semántica). La traduccion de Lefebvre insiste sobre la particularidad de esta escritura, capaz de dar "vida” a las palabras, llevándolas a encontrarse en un sentido completamente diferente y nuevo respecto del que evocaría su puro valor de imagen.
}

2 S. Freud (1897). Manuscrito M.

3 D. Humphreys (1999). David Lynch: Stereo-Unheimlichkeit, Objetos Caídos No. 4, p.27-42, Santiago, ed. Universidad Diego Portales.

$4 \quad$ S. Freud (1910). Un recuerdo infantil de Leonardo da Vinci. 
5 La palabra para calificar los personajes secundarios y mudos que constituyen la escena es en francés «figurant», lo que da bien cuenta de la importancia de estos personajes en la organización de la puesta en escena: los elementos periféricos a la trama son precisamente los que permiten de establecer las circunstancias, el tiempo, la calidad de la escena. Ellos la configuran.

6 Caché, largo-metraje franco-austriaco de 2005 dirigido por Michael Haneke, con Juliette Binoche, Daniel Auteuil, Annie Girardot. Obtuvo la palma de oro en Cannes por la puesta en escena el mismo año.

7 Es solo en el año 2012, durante el gobierno de François Hollande, que el estado francés reconoció por primera vez la violencia de estos eventos en los que los argelinos manifestaban por el derecho a la independencia fueron asesinados.

$8 \quad$ S. Freud, la interpretación de los sueños, OC. Tomo 1, Madrid, p. 517.

9 S. Freud (1895). Entwurf einer Psychologie IN: Gesammelte werke, Nachtragsband. Frankfurt am Main, S. Fisher, 1987, p. 389.

10 M. David-Ménard. Corps et langage en psychanalyse. Paris, Campagne Première, 2014.

11 S. Freud. Carta a Fliess del 6.12.1896. IN : Naissance de la psychanalyse, Paris, PUF 1973, p. 153-160 (trad. libre).

12 J. Lacan. Le séminaire livre 7, L’Ethique de la psychanalyse (1959-1960). Paris, Seuil, 1986 (trad. libre).

13 M. David-Ménard. Corps et langage en psychanalyse, op.cit.

14 Freud, Manuscrito M.

15 J. Lacan. L'acte. Seminario inédito, clase del 6.3.1968, trad. libre.

16 Forma que Deleuze llama «visagéité». 